\title{
ALTHUSSER Y ROZITCHNER: \\ DOS CAMINOS HACIA SPINOZA
}

\section{ALTHUSSER AND ROZITCHNER: \\ TWO PATHS TO SPINOZA}

\author{
Pedro YAGÜE* \\ Universidad de Buenos Aires
}

Resumen: En el presente trabajo realizaremos un contrapunto de los caminos que llevaron a las filosofías de Louis Althusser y de León Rozitchner desde los problemas abiertos por el marxismo hacia la filosofía de Spinoza. Intentaremos pensar el momento de la vida de cada teoría en que Spinoza hizo su irrupción, qué problemas teóricos condujeron en cada caso a un encuentro conceptual con el pensamiento del filósofo holandés y, en este sentido, qué aspectos de la filosofía de Spinoza fueron retomados. En el caso de Althusser, el hincapié aparecerá en Spinoza como antídoto contra toda teleología y como portador de una concepción materialista de la imaginación; en el caso de Rozitchner, Spinoza se hará presente en tanto ilumina una racionalidad profunda asociada a la vida afectiva de los hombres. De esta manera intentaremos contraponer la constitución de dos caminos bien distintos, para así dar cuenta de la complejidad y riqueza que el pensamiento de Spinoza adquiere a la luz de los problemas abiertos por la tradición marxista.

Palabras clave: Spinoza, Althusser, Rozitchner, materialismo, afectividad.

AвSTRACT: In the present work we will perform a counterpoint of the paths that led the philosophies of Louis Althusser and Leon Rozitchner from the problems opened up by Marxism toward the philosophy of Spinoza. We will try to consider the moment in the life of each theory in which Spinoza appeared, what theoretical problems led, in

* Investigador doctoral de la Universidad de Buenos Aires y docente de la materia Teoría Política y Social I de la carrera de Ciencia Política. E-mail: yague.pe@gmail.com. 
each case, to a conceptual encounter with the thought of the Dutch philosopher and, in this sense, what aspects of Spinoza's philosophy were taken up again. In Althusser's case, the emphasis will be on Spinoza as an antidote against all teleology and as the bearer of a materialistic conception of the imagination; in the case of Rozitchner, Spinoza is present insofar as he illuminates a deep rationality associated with the affective life of men. In this way we will try to compare the constitution of two very different paths, in order to account for the complexity and richness that Spinoza's thinking acquires in the light of the problems opened up by Marxist tradition.

KeYwords: Althusser, Rozitchner, materialism, affectivity.

\section{Introducción}

El pensamiento de Spinoza ha logrado introducirse, principalmente en Francia durante los ańos 60, en las disputas teóricas del marxismo. El pensador maldito de la filosofía moderna, quien fuera expulsado a sus veinticuatro años de su comunidad de origen, lograría actualizar la crítica de lo teológico-político, tiempo después de su muerte, en una de las teorías más radicales del siglo XX. La presencia de Spinoza en la teoría social contemporánea encuentra su antecedente fundamental en dos trabajos de Louis Althusser: Para leer El Capital y La revolución teórica de Marx. Ambos textos de 1965 introdujeron, a partir de la utilización de nociones tales como "proceso sin sujeto" o "causalidad estructural", lineamientos spinozianos en las discusiones políticas y filosóficas marxistas. Esta segunda Spinoza-Renaissance (segunda en relación con el primer renacimiento spinoziano en las lecturas de Goethe, Lessing, Mendelssohn, etc.) dio lugar a una productividad política y teórica que se propuso disputarle a finales del siglo XX la hegemonía hermenéutica a la ortodoxia marxista. Como plantea Althusser en Elementos de autocrítica (2015), Spinoza abrió el camino hacia una dialéctica materialista no hegeliana. La ontología de Spinoza proporcionó a los conceptos de Marx una nueva forma de concebir la historia y el cambio social.

¿Cuándo y por qué llega un filósofo a la vida teórica de otro? Es una pregunta difícil de contestar. Lo cierto es que la afinidad del pensamiento marxiano con el de Spinoza se remonta al período de juventud del teórico de Tréveris, período durante el que estudió detalladamente los textos spinozianos y realizó, en 1841, un cuaderno de extractos del Tratado teológico-político. Como bien señala Miguel Abensour (1998), lo que el joven Marx tomó de Spinoza no fue sólo la tesis a favor de la libertad de filosofar, sino también la necesidad de destruir el nexo teológico-político para la fundación de una Res publica. 
Más allá de esta influencia de Spinoza en los textos marxianos de juventud, es en el llamado "Marx maduro" donde, según Althusser, se encuentra la potencia del encuentro conceptual con el filósofo holandés. Es en la Crítica de la economía politica y en El Capital donde el teórico de Tréveris despliega sólidamente la dimensión materialista histórica que, a partir de los años 60 , será articulada con el pensamiento de Spinoza. Habría que señalar que Marx, a diferencia de los spinozistas contemporáneos, consideró al filósofo holandés como un pensador de la tradición idealista. Cabe retomar, en este sentido, los aportes de Carlos Casanova (2007), quien afirma que la relación teórica entre Marx y Spinoza va más allá de su lazo histórico: depende de una afinidad conceptual entre ambas producciones teóricas.

Pierre Macherey (2006) afirma que la imagen de Spinoza en la filosofía contemporánea europea se encontró, hasta las interpretaciones de Deleuze (1968) y Matheron (1969), condicionada por la lectura que Hegel había hecho de él. Esta renovada interpretación francesa, sumada a los aportes de Althusser, impulsó a distintos pensadores (dentro de los que se destacan, entre otros, Étienne Balibar, Pierre Macherey y Antonio Negri) a reactivar y reconstruir la potencia teórica y política de Marx principalmente a partir de su vinculación con Nietzsche, Maquiavelo y el filósofo holandés. Por otro lado, un Spinoza anteriormente ligado al iusnaturalismo liberal encontró en los conceptos marxianos elementos para el desarrollo de una perspectiva materialista. Se trató entonces de una reinterpretación recíproca, de una composición conceptual surgida del encuentro entre un Marx no hegeliano y un Spinoza no individualista ni liberal.

Por estos mismos años, del otro lado del Océano Atlántico, un profesor argentino exiliado en Venezuela se encontraba realizando una articulación similar: Spinoza y Maquiavelo con Clausewitz, Marx y Freud. "Tiempos de retroceso, tiempos para tomar distancia", escribía. "Tiempos para pensar lo que la acción en su urgencia esquivó. Tiempos para traer saberes olvidados, viejos signos animados que vienen desde muy lejos, de hombres que ya son sólo polvo" (Rozitchner, 1998: 11). Se trata de León Rozitchner, quien se había licenciado y doctorado en Francia durante los años 50. Su formación durante esos años se encontró fuertemente marcada por el cruce entre fenomenología y marxismo que buena parte de la intelectualidad parisina (representada principalmente bajo las figuras de Sartre y Merleau-Ponty) estaba realizando. Fue, justamente, desde los problemas teóricos abiertos por este cruce que León Rozitchner llegó a la figura del filósofo holandés. Rozitchner advertía en los conceptos de Spinoza la 
posibilidad de continuar líneas inconclusas del pensamiento marxiano. En este sentido podríamos recuperar lo señalado por Miguel Abensour, quien sostiene, con respecto al pensamiento del teórico alemán, que lo que se buscó durante los años sesenta y setenta fue "hacerlo reemerger como una tensión interna a su pensamiento y develar en la obra de Marx [...] la presencia de algunas virtualidades de una modernidad inconclusa" (1998: 25).

La irrupción de Spinoza ha abierto diferentes caminos al interior del pensamiento marxista. La filosofía y el lenguaje spinozianos penetraron como una bocanada de aire fresco en una época que solicitaba ser ventilada. No todas las teorías ni todos los pensadores llegaron a sus textos por los mismos motivos; no todos eligieron al mismo Spinoza a la hora de establecer una alianza con su pensamiento. En la amplia gama de composiciones teóricas que vinculan a Marx con el filósofo holandés nos encontramos con dos filosofías muy diferentes: la de León Rozitchner y la de Louis Althusser. El primero, ignorado por el segundo; el filósofo francés, enemigo teórico -entre tantos otros- del argentino. A pesar de las enormes distancias que pareciera haber entre ambos, hay entre ellos, tal vez, más afinidades de lo aparente. Ambos fueron conscientes de la exigencia que la teoría marxiana se solicita a sí misma: ser sacudida por el devenir de los tiempos históricos. Y ambos recurrieron casi al mismo tiempo a las mismas tradiciones a la hora de emprender dicha tarea: el psicoanálisis, Maquiavelo y Spinoza.

En el presente trabajo intentaremos hacer un contrapunto de los caminos de ambas filosofías. Intentaremos pensar el momento de la vida de cada teoría en que la filosofía de Spinoza hizo su irrupción, qué problemas teóricos abiertos por la tradición marxista condujeron en cada caso a un encuentro conceptual con el pensamiento del filósofo holandés y, en este sentido, qué aspecto de la filosofía de Spinoza fue retomado. No se trata de comparar y comparar con la esperanza de que algo quede, sino de contraponer la constitución de dos caminos bien distintos, para así dar cuenta de la complejidad y riqueza que el pensamiento de Spinoza adquiere a la luz de los problemas teóricos abiertos por la tradición marxista.

\section{El antídoto materialista}

Un acto de honestidad nos obliga a leer los escritos althusserianos del año 1965 a la luz de las afirmaciones realizadas en Elementos de autocrítica. Más aún si-como es nuestro caso- nos proponemos pensar los caminos que condujeron 
a la teoría althusseriana hacia los textos de Spinoza. Fue en la búsqueda de una filosofía para el marxismo que Louis Althusser se encontró con el pensamiento del filósofo holandés. Entre 1972 y 1974 Althusser escribió dos ensayos reunidos y titulados como Elementos de autocrítica en los que se propuso, por así decirlo, ampliar lo realizado en la Respuesta a John Lewis: especificar el alcance de sus desarrollos teóricos y responder algunas de las críticas recibidas durante finales de los años sesenta. Allí realizó por primera vez un examen crítico de La revolución teórica de Marx y Para leer El Capital, obras iniciáticas de la filosofía althusseriana en que la figura de Spinoza había sido rescatada como antecedente filosófico de Marx. Ambos trabajos, escribiría Althusser a comienzos de los años setenta, se encontraron afectados por un problema al que dio el nombre de "desviación teoricista”. El filósofo francés buscaba aclarar el alcance y la especificidad de nociones previas tales como la de "corte" o la de "práctica teórica". Otro elemento que Althusser se vio obligado a aclarar en Elementos de autocrítica fue el referido al estructuralismo: "no hemos sido estructuralistas [...] hemos sido spinozistas" (Althusser, 2015: 193). Spinoza le había permitido escaparle eficazmente a la categoría de sujeto y a toda noción ligada al origen. Fue el pensamiento de Spinoza la pasión que dominó a Althusser en el transcurso de aquellos años.

Los problemas teóricos abiertos por los textos del filósofo holandés, decíamos, se encontraban ya presentes en sus dos obras más importantes de los años sesenta. Al principio de Para leer El Capital Louis Althusser señala que fue Spinoza el primer filósofo que planteara el problema conjunto de la lectura y de la historia a la luz de la afirmación de la opacidad de lo inmediato. El filósofo holandés aparecería, de esta manera, iluminando una zona de la teoría del conocimiento en la que teoría y práctica encontrarían una relación dialéctica y activa. Según Althusser El Capital representaría, en este sentido, una evolución spinozista con respecto a los Manuscritos marxianos de 1844 por el hecho de tomar "la exacta medida de una distancia, de un desplazamiento al interior de lo real" (Althusser, 2012: 22). Esto puede ser afirmado tanto por el examen de Marx relativo a la circulación del valor como por la problematización en torno al carácter fetichista de la mercancía. Althusser pareciera en este texto interesarse sobre todo por la gnoseología spinoziana que le permitía separar, por ejemplo, la idea de círculo del círculo mismo, la idea de perro de la del animal que ladra. Permitía evitar la identificación entre el objeto de conocimiento y el objeto real.

Vemos entonces cómo ya desde los primeros escritos de la obra de Louis Althusser el filósofo holandés funcionó como un antídoto contra las mistificaciones de la filosofía hegeliana. Spinoza cumplió, desde el comienzo, 
el papel de antídoto materialista contra el idealismo residual de la filosofía de Hegel. Esta consideración sobre Spinoza se encuentra también presente en una larga y bella nota al pie de La revolución teórica de Marx. En el capítulo que se refiere al problema de la historia al interior del pensamiento de juventud del teórico de Tréveris, Louis Althusser incorpora una referencia en la que afirma que si se quiere encontrar un antepasado filosófico a Marx en relación con el problema del conocimiento y la ideología "más que a Hegel, es necesario dirigirse a Spinoza” (Althusser, 1971: 64). El filósofo holandés, nos dice Althusser, es agua viva que todavía no ha corrido. Su potencia teórica, contenida, pareciera haber esperado a la llegada de nuevos tiempos para poder desplegarse en su plenitud.

Según el teórico francés, el concepto spinoziano de superstitio es, en varios sentidos, afín a la noción marxiana de ideología. Spinoza, en el Tratado teológicopolítico, concibe a la superstición religiosa como la fuerza sobre la que se apoya la monarquía para hacer que los hombres luchen por su propia esclavitud como si se tratara de su libertad. El sentido político de la religión implicaría, de esta manera, algo más que un engaño: la superstición es una forma de vida. Althusser encontró tanto en el apéndice del libro I de la Ética como en el Tratado teológicopolítico los primeros esbozos de una crítica materialista de la ideología como "realidad imaginaria". Spinoza, señala Althusser en La única tradición materialista (2007), proporciona una concepción de ideología como la expresión de una forma de vida en la que la experiencia del mundo imaginario es interpretada como Lebenswelt. Spinoza da lugar, señala Louis Althusser en su autocrítica, a un "materialismo de lo imaginario" (Althusser, 2015: 196).

En Spinoza, nos dice el filósofo francés, la imagen es alucinatoria por esencia. Es lo imaginario, lo ideológico como sistema estructurado, lo que constituye un mundo propio y vivido. A partir de la clásica distinción spinoziana de los géneros de conocimiento el filósofo francés señala que lo imaginario no ocupa en la filosofía de Spinoza el lugar de una mera categoría ni de una función psicológica, sino el de la constitución de un mundo. Con esta afirmación el filósofo francés busca desprenderse del subjetivismo cartesiano y de las consecuencias gnoseológicas y políticas que de él se desprenden. Al igual que en el caso de Hegel, la filosofía de Spinoza cumple contra Descartes un papel de antídoto materialista. 
En 1972 en Elementos de autocrítica Althusser sostiene:

Pero entonces he aquí la gran objeción: ¿por qué, pues, remitirse a Spinoza cuando se trataba de ser simplemente marxistas? ¿Por qué este rodeo? ¿Era necesario? ¿Y qué precio se ha pagado por ello? El hecho es: nosotros hemos dado en los años 1960-1965 este rodeo y lo hemos pagado bastante caro. (Althusser, 2015: 193)

Althusser señala que es la especificidad del trabajo filosófico el que solicita constantemente la búsqueda de rodeos y retrocesos. Eso mismo, nos dice, es lo que ha hecho el propio Marx a lo largo de su vida política y teórica. Pero la pregunta persiste: ¿por qué Spinoza? Althusser responderá que el rodeo por el pensamiento del filósofo holandés le sirvió para poder "ver un poco más claro en la filosofía de Marx" (Althusser, 2015: 195). No sólo eso: la filosofía de Spinoza le permitió a Althusser encontrar una filosofía radical que pudiera sostener el pensamiento marxiano por fuera del misticismo y la teleología de Hegel. Su filosofía porta una radicalidad que se advierte desde el principio de su Ética. Spinoza comienza su obra filosófica mayor partiendo de la definición de la causa sui: "Por causa sui entiendo aquello cuya esencia implica la existencia, o, lo que es lo mismo, aquello cuya naturaleza sólo puede concebirse como existente" (Spinoza, 2012b: 9). Con este simple comienzo y al definir a Dios como la única sustancia existente y causa de sí misma, Spinoza desarticula toda teleología posible, en tanto esta sustancia que llama Dios (o naturaleza) al producirse, produce también la potencia de las cosas singulares que en ella existen (bajo la forma de modos y atributos). De esta manera Spinoza habilita una nueva concepción epistemológica. Se abre así una inmanencia radical, en la que el efecto participa en la producción de su causa sin la presencia de elementos teleológicos ni finalistas.

El rodeo por Spinoza nos descubría así por diferencia una radicalidad de la que carece Hegel. En la negación de la negación, en la Aufhebung (= superación que conserva lo que supera), él nos permitía descubrir el Fin: forma y lugar privilegiados de la "mistificación" de la dialéctica hegeliana. (Althusser, 2015: 196)

Podríamos decir, a partir de los análisis del propio Althusser, que en la filosofía de Hegel existe una ontología de lo necesario que Spinoza desarma, sin por ello desarmar el movimiento de la historia que su filosofía conlleva. El rodeo por los conceptos del filósofo holandés es lo que le permite a Althusser deshacerse de las mistificaciones hegelianas, sin por ello abandonar los aspectos 
de su obra que dieron lugar a varios de los desarrollos del materialismo histórico de Marx. Spinoza, junto a Bacon y Bruno, afirma Rodolfo Mondolfo (2006), dieron impulso a la conquista de lugares antes inexplorados en el conocimiento de la historia y de la acción. La idea de una transformación continua de los resultados en capacidades nuevas, que, a la vez, significan siempre nuevas exigencias y por lo tanto nuevas creaciones, es una concepción de la historia en la que Spinoza, según el profesor italiano, precede a Marx. Podríamos afirmar, retomando lo señalado por Mondolfo, que la obra del filósofo holandés le permite a Althusser encontrar argumentos materialistas para así romper con la concepción teleológica de la historia presente en el pensamiento de Hegel, aunque, claro está, reteniendo el concepto hegeliano de proceso.

Es, sin embargo, con los desarrollos tardíos del pensamiento de Louis Althusser, con su materialismo del encuentro, que Spinoza termina de constituir un camino hacia la profundización de los problemas abiertos por la tradición marxista. En estos trabajos la teleología es entendida como una forma de idealismo encubierto: el verdadero materialismo se encuentra gobernado por el azar. De allí la importancia de la noción de clinamen en el pensamiento althusseriano de este período. Es el reino de las desviaciones impensables, de los encuentros impredecibles. La historia, dirá Althusser, "no es más que la revocación permanente del hecho consumado por parte de otro hecho indescifrable a consumar, sin que se sepa, ni de antemano ni nunca, dónde ni cómo se producirá el acontecimiento de su revocación" (Althusser, 2002: 39). Es justamente el carácter inmanente y autopoiético de la sustancia spinozista el que le permite a Louis Althusser desarrollar una concepción aleatoria del comienzo del capitalismo. El modo de producción capitalista, señala, "ha nacido del encuentro entre 'el hombre de los escudos' y el proletario desprovisto de todo excepto de su fuerza de trabajo" (Althusser, 2002: 64). Esta idea del encuentro, tan presente en las filosofías de Maquiavelo y Spinoza, nos obliga a pensar una vez más las afinidades entre ambos pensadores, afinidades que permitieron que ambas teorías lograran oxigenar el camino de un marxismo asfixiado por los avatares del socialismo real. Esta misma fórmula del encuentro de los hombres de escudos con el proletariado expropiado de sus tierras y de sus medios, es también utilizada en la Iniciación a la filosofía para los no filosofos, texto en que desarrolla más ampliamente la importancia de los descubrimientos técnicos y científicos que pudieron dar lugar a una constitución duradera de dicho encuentro histórico. 
En su texto La única tradición materialista, Louis Althusser afirma que su primer encuentro con la obra de Spinoza le disparó inmediatamente una aparente contradicción: ¿cómo alguien que había fundado su pensamiento en el more geometrico podía pensar y teorizar con tal libertad? ¿Cómo un método aparentemente dogmático podía habilitar y producir una forma tan libre de pensamiento? Es, sin embargo, el rigor con el que los razonamientos se encadenan lo que le permite a la filosofía de Spinoza producir un nuevo espacio teórico.

Por eso afirmábamos al comienzo del trabajo: la filosofía de Louis Althusser llega a la de Spinoza a partir de los problemas abiertos por los textos y discusiones de la tradición marxista. Fue esa búsqueda de un sustento filosófico materialista la que habilitó el encuentro con determinados aspectos -y no con otros- de la obra del filósofo holandés. Spinoza, como ya señalamos, aparece a lo largo de los textos de Althusser como un eficaz antídoto contra las mistificaciones residuales del pensamiento de Hegel. Los conceptos del filósofo holandés, como vimos anteriormente, encuentran su alcance tanto en el campo gnoseológico como en el campo histórico. La sustancia de Spinoza como destructora de toda teleología posible, la distinción entre los géneros de conocimiento como la posibilidad de constituir un nominalismo materialista, y la realidad imaginaria como la posibilidad de analizar desde un punto de vista materialista e histórico la vida ideológica de los hombres, fueron los principales aspectos que Louis Althusser retomó de la obra del filósofo holandés. Spinoza fue uno de los caminos subterráneos por los que Althusser emprendió su corriente materialista.

\section{El saber de los cuerpos}

Desde mediados de los años cincuenta hasta el final de su vida, la obra de León Rozitchner se encontró animada por el intenso cruce entre fenomenología y marxismo. Fueron las preguntas allí encontradas las que motorizaron los largos años de su indagación filosófica. Fue a partir de este encuentro conceptual que las diferentes vertientes de su obra se fueron desplegando. Los problemas abiertos por la fenomenología obligaron a Rozitchner a incorporar nuevos lineamientos teóricos al interior de su filosofía materialista. Al mismo tiempo, la imposibilidad de la fenomenología de dar cuenta del tránsito a través del que la conciencia se constituye como tal posibilitó en su teoría, por ejemplo, la incorporación de los desarrollos del psicoanálisis freudiano a la pregunta por la constitución material de la subjetividad histórica. Es a partir de los problemas 
abiertos por el cruce entre fenomenología y marxismo que debe entenderse la singular inserción del pensamiento de Spinoza en la obra de León Rozitchner.

Decíamos al comienzo que nunca es del todo claro cómo la obra de un filósofo llega a la vida de otro. Sin embargo, el encuentro de León Rozitchner con los textos de Spinoza podría ser precisado con cierta exactitud. Sucedió en Venezuela, a mediados de los años setenta. Rozitchner se había exiliado en dicho país meses antes del golpe de estado que en 1976 pondría Jorge Rafael Videla a la cabeza del gobierno argentino. Durante los primeros años de su exilio el teórico de Chivilcoy dictó clases de Ética en la Facultad de Filosofía de la Universidad Central de Venezuela, donde además estuvo a cargo de un seminario sobre el Tratado teológico-político. Fue allí donde el encuentro de su filosofía con la de Spinoza se produjo; encuentro que tomaría consistencia desde aquel entonces hasta el final de su vida.

Durante los primeros años de su exilio en Caracas León Rozitchner comenzó a escribir el libro Perón: entre la sangre y el tiempo. Lo inconsciente en la política, que sería publicado por primera vez en 1984. A lo largo de las muchas páginas de este libro el filósofo argentino se propuso pensar lo sucedido en su país durante los años setenta. Era necesario pensar lo que "la acción en su urgencia esquivó" (Rozitchner, 1998: 11). Para ello Rozitchner se dispuso a configurar una nueva caja de herramientas con viejos saberes olvidados, con filosofías no escuchadas por la izquierda argentina de aquellos años; filosofías que permitieran echar algo de luz sobre "el sentido de la propia vida que antes no pudimos ver" (Rozitchner, 1998: 11). Había que reanimar los conceptos de una izquierda que, convencida en las leyes de la historia, había menospreciado la importancia política de las cuestiones subjetivas. Había que, desde la filosofía y la teoría política, conquistar un nuevo espacio desde el que analizar el drama de la historia argentina reciente. Maquiavelo, Spinoza, Marx, Freud y Clausewitz: esas fueron las herramientas elegidas por León Rozitchner para pensar lo no pensado por la militancia y la intelectualidad argentina.

En el prólogo a la primera edición de su libro sobre Perón el teórico argentino explica el porqué de la elección de esas viejas filosofías. Luego de analizar la relevancia política y teórica de Maquiavelo, Rozitchner se refiere al filósofo holandés:

Spinoza, también. De él se dijo: "cada filósofo tiene dos filosofías, la propia y la de Spinoza". Su filosofía está detrás de cada uno de nosotros, y nos invita a convertirnos en el lugar donde se elabora, como experiencia de vida, lo que 
la mera reflexión sólo enuncia como saber, y enfrentar entonces el riesgo de un nuevo e ignorado poder. Por eso nos advierte: "nadie sabe cuánto puede un cuerpo". El saber se despliega sólo luego de descubrir y ejercer este poder. (Rozitchner, 1998: 12)

Es en la corporeidad más íntima, nos dice Rozitchner, donde el verdadero contrapoder se esconde. Los cuerpos tienen una historia que no es sólo la de las estructuras que en ellos se despliegan. El filósofo argentino se opone, con Spinoza como escudo, a cierto estructuralismo que, desechando la noción de sujeto, veía a los hombres como meros soportes de estructuras anónimas. Como si en ellos nada se produjera. Frente a esta concepción León Rozitchner se resiste a abandonar la noción de sujeto, a quien define como núcleo de verdad histórica. Lejos de recuperar dicha categoría desde una perspectiva idealista, Rozitchner elabora una concepción materialista e histórica del sujeto construida principalmente a partir de los desarrollos de Merleau-Ponty. Es el silencioso comercio con los hombres, la naturaleza y las cosas, el que hará del cuerpo el lugar de la elaboración de una afectividad; el lugar de la elaboración de un saber que cada uno portará como índice de su inserción histórica en el mundo.

La idea del sujeto como núcleo de una verdad material e histórica que en él se elabora, implica, como señalamos, un movimiento teórico a través del que Rozitchner buscó romper con las tradiciones estructuralistas que veían en cada individuo el mero soporte de poderes anónimos. Y fue en el marco de esta batalla que el pensamiento de Spinoza fue incorporado: su filosofía invitaba a pensar al cuerpo como fábrica de imágenes y afectos, a pensar al cuerpo histórico como el lugar de una resistencia posible. Hay efectivamente una determinación histórica que organiza al sujeto como sometido, nos dice Rozitchner, pero también hay en él oposiciones que pueden hacer de ese cuerpo sensible el lugar contradictorio y productivo de una resistencia. Esto querrá decir, entre otras cosas, que cada uno es el lugar humano en el que la verdad de lo colectivo, con sus tensiones y contradicciones, se elabora.

Hay en cada hombre, nos dice el filósofo argentino, un nuevo e ignorado poder. Ese poder es la potencia de lo que los cuerpos, en su encuentro, pueden: es el poder de lo colectivo. "El poder colectivo", señala Rozitchner en el prólogo al Perón, "se revela desde el propio cuerpo individual amplificado cuando superamos la cerrazón sensible que el terror nos impuso al separarnos de los demás" (Rozitchner, 1998: 12). Spinoza, en este sentido, aparece en la obra de Rozitchner como un camino para profundizar su análisis relativo al terror histórico que a los hombres separa. Con esta categoría León Rozitchner se 
propone analizar el proceso a través del cual el reconocimiento de la afectividad común se disuelve, deshermanando a los hombres, separándolos de lo que ellos en su reunión pueden. El terror es la cerrazón en uno mismo, el aislamiento con respecto a los otros y al mundo. La búsqueda de un regocijo interno, de un refugio alucinado, posibilitado por la negación de la materialidad histórica constitutiva de la propia vida. Es aquí donde la potencia teórica de Spinoza viene a alimentar los desarrollos de la filosofía de Rozitchner. El filósofo holandés nos habla de la eficacia imaginaria del poder religioso como poder político en la separación histórica de los hombres.

El pensamiento del filósofo argentino con respecto al problema histórico del terror recuerda un bello pasaje del Tratado político - de evidente influencia maquiaveliana- en el que Spinoza tematiza este mismo problema en términos muy similares a los de León Rozitchner:

De una sociedad cuyos súbditos no empuñan armas, porque son presa del terror, no cabe decir que goce de paz, sino más bien que no está en guerra. La paz, en efecto, no es la privación de guerra, sino una virtud que brota de la fortaleza del alma [...]. Por lo demás, aquella sociedad cuya paz depende de la inercia de unos súbditos que se comportan como ganado, porque sólo saben actuar como esclavos, merecen más bien el nombre de soledad que de sociedad. (Spinoza, 2013: 151)

El terror es justamente aquello que aleja a los hombres de su verdadero contrapoder, de la fuerza desconocida que en ellos se aloja. Es aquello que los separa e impide la concordancia de los cuerpos que sienten y piensan. De allí la importancia de lo colectivo, la importancia de las masas y de la concordancia de todos en todas las cosas. Casi diez años después de la publicación del Perón, León Rozitchner retomará, en este mismo sentido, un pasaje spinoziano del Tratado teológico-politico en el que se afirma que las masas son "femeninas". A partir de esta sentencia, el filósofo argentino afirma una vez más el carácter pulsional y afectivo de las masas: "cuando los hombres reunidos descubren el poder de sus cuerpos reunidos, vuelve a despertarse en ellos un poder de resistencia" (Rozitchner, 1998: 13), nos dice, vuelve a despertarse el carácter espontáneo, carnal y vivo de las masas.

Pero este hombre maldito [Spinoza], que enfrentó la cólera de los hombres que hablaban en nombre de Dios utilizando como recurso el terror, escribió luego la Ética, que no es más que un libro. Pero no es sólo un libro más: la Ética de Spinoza es un tratado de insurgencia político-moral. Nos 
muestra, más allá de las apariencias, dónde reside el verdadero poder: desde la sabiduría aún inconsciente de nuestro propio cuerpo. [...] Aun la barbarie, en su terror inmisericorde, toca y penetra por efracción la trama compleja de un cuerpo -individual y social- que fue doblegado, aterrorizado ante su fuerza. Pero esa trama viva, resistente, preexiste al ejercicio desnudo del poder que la somete, y permanece contenida: está oculta porque desconocemos nuestro propio poder que, sin embargo, debemos despertar y comprender. (Rozitchner, 1998: 13)

Es exactamente en este sentido que la filosofía de Spinoza realiza su aporte al interior de la teoría de León Rozitchner. Los cuerpos tienen una historia que, aunque no consciente, se presenta como el insumo desde el que combatir el terror histórico que a los hombres separa. Hay, por lo tanto, un poder del cuerpo que excede a todo saber. Es una trama viva que en él resiste, y que preexiste al poder que busca someterla. Por eso es que el sometimiento nunca es total: si lo fuera, no habría resistencia posible. Rozitchner no ve a los cuerpos como el resultado del encuentro aleatorio de materia detenida por el aparato burgués, sino que se propone rescatar al cuerpo en su dimensión sensible como lugar de resistencia y creación. Es en este sentido que la filosofía de Spinoza realiza su aporte al interior de la de Rozitchner.

En el año 2004, en el marco del Ciclo de pensamiento contemporáneo, León Rozitchner dictó una conferencia en la Biblioteca Nacional Argentina titulada "La cruz del fin del mundo (Spinoza, Marx, Freud y Lévi-Strauss)". En ella el filósofo argentino señalaba la crisis de la razón con la que el presente político intentaba pensarse a sí mismo: "El pensamiento, en el cual estábamos todos incluidos, no pudo pensar esto que uno ve aproximarse" (Rozitchner, 2015a: 150). A lo largo de la exposición, Rozitchner afirma la carencia en el campo de lo político, de una teoría que se proponga pensar la implicación real y efectiva de la mitología cristiana en el orden social capitalista ${ }^{1}$. Fue en el marco de este problema que la filosofía de Spinoza volvía a aparecer explícitamente: fue desde

\footnotetext{
${ }^{1}$ Por una cuestión expositiva no desarrollaré en este texto la relación que Rozitchner establece entre cristianismo y capitalismo. Resumidamente podría señalarse que, para el filósofo argentino, todo cuerpo humano realiza un tránsito desde la infancia primera hacia la razón cultural que se encuentra mediado y organizado por lo que Rozitchner llama mitología. Ella es la que organiza la percepción de uno mismo, del mundo y de los otros, y, por lo tanto, la que permanece como fundamento de las relaciones sociales. Es la mitología cristiana, seńala Rozitchner, la que organiza el tránsito hacia la razón occidental sobre la que el orden capitalista se asienta.
} 
su condición de racionalista judío, señalaba Rozitchner, que el filósofo holandés (al igual que Marx, Freud y Lévi-Strauss) se había acercado al desarrollo de dicha crítica.

La filosofía de Spinoza recupera el fundamento humano sensible de la vida, presente tanto en la naturaleza como en el proceso por el que los hombres se producen a sí mismos. Es por ese camino que su filosofía recupera la importancia de la corporeidad gestadora de la mujer, en tanto experiencia primera por la que todo cuerpo histórico pasó. La relación estrecha entre terror religioso y terror político, permite a Rozitchner poner a la filosofía spinozista a pensar las implicaciones subjetivas del terror cristiano en el capitalismo. A su vez, la idea de los cuerpos encontrados que conforman un gran cuerpo, nos dice León Rozitchner, da lugar a otra concepción de la democracia. A una forma material e histórica de la democracia, no regida por principios externos a sus propios elementos constituyentes ${ }^{2}$. Porque el encuentro de los cuerpos da lugar a nuevas formas de organización de las que no se puede saber "qué poder tiene, y que por lo tanto es un poder que de alguna manera requiere la experiencia fundante del desarrollo histórico para poder hacer aparecer todas las posibilidades de vida que el cuerpo del hombre encierra" (Rozitchner, 2015a: 158).

En los años finales de su vida, el filósofo argentino publicará Materialismo ensoñado, obra que, de alguna manera, condensa las investigaciones desarrolladas a lo largo de su vida. Por el estilo y la retórica de dicho texto, pocos nombres aparecen mencionados o citados en él. Uno es el de Spinoza. Allí aparecen los desarrollos spinozianos relativos a "la idea de la idea" presentes en el Tratado de la reforma del entendimiento. El nacimiento de toda idea, nos dice Rozitchner, siempre se encuentra directamente ligado a la historia de un cuerpo, con sus afectos y deseos. Es el cuerpo la condición de posibilidad para la aparición de todas las demás ideas. Y esto nunca debe ser olvidado. Rozitchner solía decir que en el campo de la filosofía académica se olvidó la premisa afectiva que fundamenta todo pensamiento. Son ideas sin materialidad sintiente, sin un cuerpo cálido que les de vida.

\footnotetext{
${ }^{2}$ Diego Tatián señala en El Don de la Filosofía (2012) que tanto Marx como Spinoza logran liberar a la comunidad política de la intrusión teológica. De allí la afinidad existente entre el concepto marxiano de "individuo social" y la concepción spinoziana de "multitud": ambas nombran una constitución de lo común práctica e históricamente abierta. Otro aporte en este mismo sentido lo realiza Étienne Balibar en Spinoza: de lo individual a lo transindividual (2009), quien relaciona la categoría simondoniana de transindividual con la concepción spinoziana de sustancia, como un producto abierto y dinámico del proceso de individuación.
} 
Spinoza, dice Rozitchner, nos muestra al cuerpo como el lugar histórico en el que las imágenes, las ideas, y los afectos se producen. Esta concepción no empirista del materialismo, permite abrir un espacio teórico desde el que pensar el proceso a partir del que la afectividad de los hombres se constituye. De allí la afinidad de la filosofía de Spinoza con la noción rozitchneriana de ensoñación: ambos ven en el cuerpo algo más que mera materia divisible y cuantificable. El filósofo holandés, en tanto racionalista judío, elabora un materialismo radical en el que las afecciones y el deseo juegan un rol fundamental. "El deseo es la esencia del hombre", nos dice en su Ética.

Es desde este punto que habría que entender la forma en que León Rozitchner llega, desde los problemas abiertos por el marxismo, a la filosofía de Spinoza. Ya desde el año 1966, en su conocida discusión con John William Cooke plasmada en su artículo "La izquierda sin sujeto", el filósofo argentino planteaba la necesidad de comprender la constitución histórica de la subjetividad a la hora de pensar una teoría revolucionaria: "Debemos descubrir una racionalidad más profunda que englobe en una sola estructura, partiendo desde la experiencia sensible de nuestro propio cuerpo, nuestra conexión perdida con los otros" (Rozitchner, 2015b: 25). Buena parte de la izquierda argentina, repitiendo la separación burguesa entre lo privado y lo público, había relegado del campo político lo más íntimo de cada sujeto. Rozitchner señalaba, en este sentido, la necesidad de atacar las categorías burguesas que perseveran escondidas en la intimidad del revolucionario de izquierda. Es de esta manera que la filosofía de Spinoza hace su aparición: otorga elementos teóricos para el análisis de este "nido de víboras" en el que lo racional y lo sensible se enlazan. Su filosofía le permite a Rozitchner profundizar su análisis en torno a la relación existente entre la constitución histórica de la subjetividad de los hombres y la totalidad concreta de la que ellos forman parte. Spinoza fue uno de los caminos elegidos por Rozitchner para el desarrollo de su materialismo ensoñado.

\section{Conclusiones}

Dos caminos diferentes llevaron a Louis Althusser y a León Rozitchner desde los problemas abiertos por el marxismo hacia la filosofía de Spinoza. Caminos diferentes, decimos, porque fueron otras las líneas desarrolladas al interior del pensamiento marxiano, y fue otro también el Spinoza recuperado por cada uno. En Althusser, como vimos, la obra del filósofo holandés juega el papel de antídoto materialista. Su filosofía fue el remedio encontrado contra las mistificaciones teleológicas del pensamiento hegeliano, todavía presentes 
en algunos lineamientos de la tradición marxista. También fue Spinoza el que abrió el camino hacia una concepción materialista e histórica de la ideología y de la vida imaginaria de los hombres. Por estos motivos, sostiene Althusser en varias ocasiones, Spinoza es uno de los principales antecesores filosóficos de Marx.

Diferente es el caso de León Rozitchner. Los conceptos elaborados por el filósofo holandés no aparecen en su obra como un antídoto, ni como correcciones materialistas frente a un desvío teleológico, sino como capaces de desarrollar vías del pensamiento marxiano presentes, aunque no del todo desarrolladas. Desde sus primeros acercamientos a la obra de Marx, León Rozitchner buscó en sus textos puntos ciegos que el teórico de Tréveris había dejado por desarrollar. Y fue allí donde apareció el problema anteriormente mencionado ligado a la subjetividad y a la constitución afectiva de los hombres.

El comienzo de la bifurcación de los caminos de León Rozitchner y Louis Althusser podría situarse teóricamente en la consideración que cada uno de ellos realiza con respecto al pensamiento marxiano de juventud, principalmente en relación con el lugar que ambos le asignan a los Manuscritos de $1844^{3}$. En 1965, contra el desprecio que el Partido Comunista Francés manifestaba contra las reflexiones teóricas, Louis Althusser publicó La revolución teórica de Marx. En dicho trabajo el filósofo francés señalaba que el fin del dogmatismo filosófico no había devuelto nunca una filosofía marxista en su integridad: sólo quedaba el desconcierto de una ciencia huérfana de filosofía. Retomando el concepto de "ruptura epistemológica", Althusser se propuso pensar en este libro el movimiento del pensamiento marxiano que culminó en la constitución de su teoría científica. En el marco de la clásica lectura althusseriana relativa a los períodos de la obra de Marx, el filósofo francés señalaba que las obras de juventud (es decir, aquellas que se extienden hasta el año 1845) se encontraron teñidas por un fuerte matiz ideológico: contaminación de la filosofía idealista alemana que se manifestó en nociones tales como esencia genérica, conciencia, etc. El fondo de la problemática de los textos de este período, señalaba Althusser, seguía siendo claramente feuerbachiano. Fue recién en La ideología alemana donde, según el filósofo francés, Marx ajustó cuentas con esta problemática. Los

\footnotetext{
${ }^{3}$ Debemos señalar al pensamiento de Gérard Granel como un antecedente que, por así decirlo, inscribe a Rozitchner en una tradición crítica con respecto a los trabajos de Althusser. En "La ontología marxista de 1844 y la cuestión del corte" Granel (2014) realiza una fuerte crítica a los trabajos atlhusserianos, en la que recupera la importancia de la noción de "sujeto" para la ontología marxista.
} 
Manuscritos significaron el primer encuentro significativo entre las reflexiones del teórico de Tréveris y la economía política, aunque todavía permaneciendo en el seno de la problemática feuerbachiana.

La comparación con el caso del filósofo argentino presenta algunas similitudes, aunque fundamentalmente diferencias. Ya en su tesis secundaria ("La negación de la conciencia pura en la filosofía de Marx"), publicada en el año 1960 en Francia, León Rozitchner sostenía que "la base filosófica del materialismo marxista, tal como aparece en alguna de las obras de juventud de Marx, constituye el fundamento indispensable que nos permitirá luego comprender sus obras maduras" (Rozitchner, 2015c: 101). No hay, según Rozitchner, una ruptura entendida en los términos problemáticos en los que Louis Althusser la plantea. El joven filósofo argentino sostenía que fue a partir de esas primeras elaboraciones filosóficas que el teórico de Tréveris pudo construir las posteriores. No le interesaba al joven Rozitchner si el verdadero Marx se encontraba en las obras de juventud o en las de madurez. Le interesaban las continuidades en su pensamiento, continuidades constitutivas de lo que en 1960 llamó una filosofía marxista.

La aparición del pensamiento de Spinoza en la filosofía de Rozitchner, como señalamos, sucedería más de diez años después de estas primeras incursiones teóricas. Allí volvía Rozitchner a sentar un posicionamiento en relación con su lectura de los textos marxianos: "Nos ofrecen un Marx sin sujeto, sin humanismo, sin lugar para la subjetividad, que sólo habría formulado una teoría reducida a las relaciones económicas de producción" (Rozitchner, 1998: 15). Marx, al igual que Freud, Spinoza y Maquiavelo, muestra, según el filósofo argentino, el lugar en el que el verdadero poder se asienta. Era el suyo, a diferencia del de Althusser, un Spinoza con sujeto.

A partir de los años noventa, en el tramo final de su obra y de su vida, León Rozitchner realizará un desplazamiento problemático en relación con la lectura y relevancia encontrada en los textos marxianos. Ya definitivamente centrado en la relación existente entre cristianismo y capitalismo, el filósofo argentino realiza una lectura de los textos marxianos centrada en El Capital, Sobre la cuestión judía y los Grundrisse. Sin embargo, su lectura de los textos marxianos seguirá siendo la misma que la del comienzo de su obra: Rozitchner buscará puntos ciegos desde los que desarrollar aspectos que Marx ha dejado inconclusos. Es desde este punto de vista que Rozitchner emprende una lectura diametralmente opuesta a la de Louis Althusser: es el momento "científico" el que obtura un conjunto de problemáticas fundamentales a las que Marx se había acercado en 
su juventud. La pregunta por la producción de los hombres por los hombres, que en la etapa madura queda totalmente subordinada a la producción de objetos, es recuperada por Rozitchner en la etapa final de su obra. Es desde allí que desarrolla un análisis de las implicancias subjetivas de la mitología cristiana y su estrecha vinculación con la forma en que los hombres se producen a sí mismos en el marco de las relaciones de producción. Aquí Spinoza vuelve a cobrar un papel importante, como señalamos, en la medida en que su filosofía habilita la posibilidad de un análisis materialista de la vida imaginaria y afectiva de los hombres.

Dos senderos diferentes, dijimos, que conducen de Marx a Spinoza. La contraposición realizada nos ayuda a advertir, en primer lugar, la complejidad de los pensamientos de Althusser y Rozitchner a la luz de los problemas advertidos y recuperados en los textos marxianos. Esto nos permite, a su vez, reconocer una vez más la riqueza analítica presente en los trabajos del teórico de Tréveris. Sus textos aparecen como una fuente inagotable para el pensamiento político y filosófico contemporáneo. En este mismo sentido, los trabajos de Spinoza brindan la posibilidad de recuperar el materialismo marxiano desde la inmanencia radical de su filosofía. Pero también, como vimos, la incorporación de nuevos problemas ligados a la vida imaginaria y afectiva de los hombres. Althusser y Rozitchner nos presentan dos caminos de una misma composición: Spinoza y Marx, Marx y Spinoza. Dos caminos encontrados, dispuestos a reinventarse al calor de los nuevos tiempos históricos.

\section{Bibliografía}

Abensour, M. (1998). La democracia contra el Estado, Buenos Aires, Ediciones Colihue. Althusser, L. (1971). La revolución teórica de Marx, Buenos Aires, Siglo veintiuno editores.

Althusser, L. (2002). La única tradición materialista, Madrid, Arena libros.

Althusser, L. (2007). La única tradición materialista, Madrid, Youcali.

Althusser, L. (2012). Para leer El Capital, Buenos Aires, Siglo veintiuno editores.

Althusser, L. (2015). La soledad de Maquiavelo, Buenos Aires, Akal.

Balibar, E. (2009). Spinoza: de lo individual a lo transindividual, Córdoba, Encuentro Grupo Editor. 
Casanova, C. (2007). “Aproximaciones al concepto de lo político en Marx-Spinoza”, en Tatián, D. (comp.), Spinoza. Tercer coloquio, Córdoba, Brujas.

Deleuze, G. (1968). Spinoza et le problème de l'expression, Paris, Minuit.

Granel, G. (2014). "La ontología marxista de 1844 y la cuestión del corte”, en Actuel Marx/ Intervenciones $\mathrm{N}^{\circ} 16$, Primer semestre, pp. 15-68.

Macherey, P. (2006). Hegel o Spinoza, Buenos Aires, Tinta Limón Ediciones.

Matheron, A. (1969). Individu et communauté chez Spinoza, Paris, Minuit.

Marx, K. (2012). Cuaderno Spinoza, traducción, estudio preliminar y notas de Nicolás González Varela, Barcelona, Montesinos.

Mondolfo, R. (2006). Feuerbach y Marx. La dialéctica y el concepto marxista de la historia, Buenos Aires, Claridad.

Rozitchner, L. (1998). Perón: entre la sangre y el tiempo. Lo inconsciente y la politica. Capital Federal, Catálogos.

Rozitchner, L. (2011). Materialismo ensoñado, Buenos Aires, Tinta Limón.

Rozitchner, L. (2015a). Escritos de fin de siglo, Buenos Aires, Biblioteca Nacional.

Rozitchner, L. (2015b). Escritos politicos, Buenos Aires, Biblioteca Nacional.

Rozitchner, L. (2015c). Marx y la infancia, Buenos Aires, Biblioteca Nacional.

Spinoza, B. (2012a). Tratado teológico-politico, Madrid, Alianza.

Spinoza, B. (2012b). Ética, Buenos Aires, Agebé.

Spinoza, B. (2013). Tratado político, Madrid, Alianza.

Tatián, D. (2012). El Don de la Filosofía, Buenos Aires, Colihue.

Recibido: 8/06/2017

Aceptado: 6/11/2017

ENDOXA está bajo una licencia de Creative Commons Reconocimiento-NoComercial-SinObraDerivada 4.0 Internacional 
